\title{
A Novel De Novo TUBB3 Variant Causing Developmental Delay, Epilepsy and Mild Ophthalmological Symptoms in a Chinese Child.
}

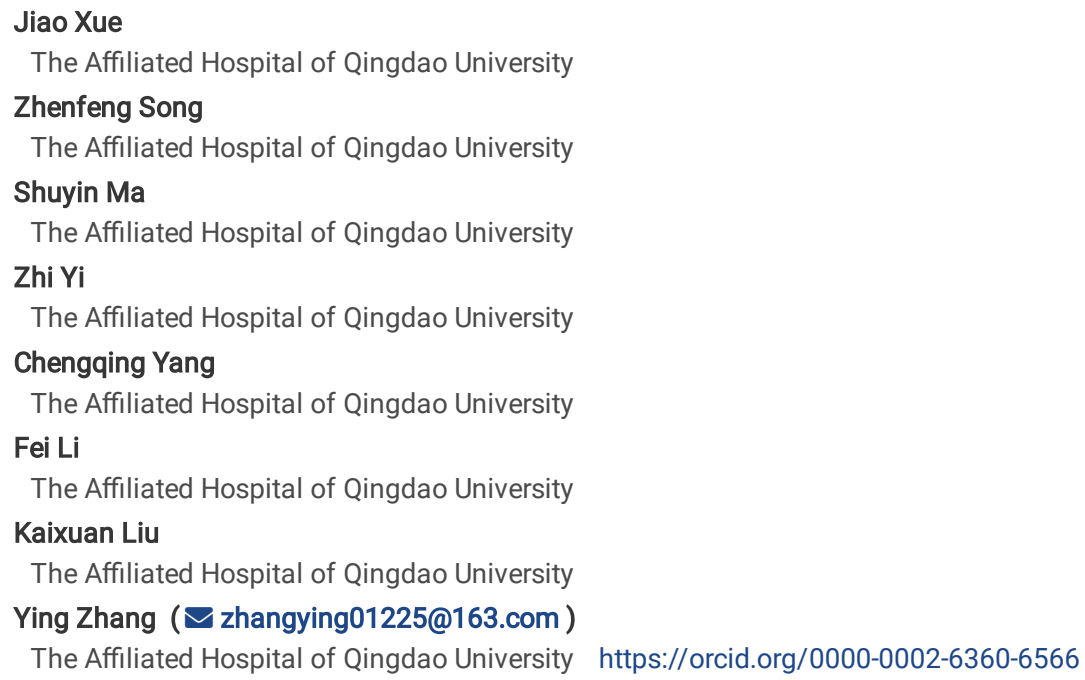

Keywords: TUBB3 gene, epilepsy, developmental delay, photophobia, elliptic pupil

Posted Date: July 7th, 2021

DOI: https://doi.org/10.21203/rs.3.rs-660033/v1

License: @) (7) This work is licensed under a Creative Commons Attribution 4.0 International License. Read Full License

Version of Record: A version of this preprint was published at Journal of Molecular Neuroscience on September 25th, 2021. See the published version at https://doi.org/10.1007/s12031-021-01909-4. 


\section{Abstract}

Heterozygous missense mutations in TUBB3 have been implicated in various neurological disorders encompassing either isolated congenital fibrosis of the extraocular muscles type 3 (CFEOM3) or complex cortical dysplasia with other brain malformations 1 (CDCBM1). The description of seizures in patients with TUBB3 mutations is rare. Here, we reported a patient who had febrile seizures before and focal seizure this time, which was diagnosed as epilepsy in combination with an abnormal EEG. MRI showed hypoplastic corpus callosum. Mutation analysis showed a novel de novo heterozygous variant of TUBB3 gene (NM_006086), c.763G>A (p.V255I). He had global developmental delay, photophobia and elliptic pupil, but lacking extraocular muscles involvement and malformations of cortical development, which might be a less severe phenotype of TUBB3 mutations. This was the first report of elliptic pupil in patients with TUBB3 mutations and expanded the spectrum of TUBB3 phenotypes. It indicated that the phenotypic range of TUBB3 mutations might be more continuous than discrete, with a severity ranging from mild to severe. Further studies are needed to elucidate the complete spectrum of TUBB3-related phenotypes.

\section{Highlights}

1. We reported a patients carrying a novel de novo TUBB3 variant.

2. The clinical presentations included global developmental delay, epilepsy, photophobia and elliptic pupil, and hypoplastic corpus callosum, without extraocular muscles involvement and MCD.

3. This was the first report of elliptic pupil in patients with TUBB3 variant and expanded the spectrum of TUBB3 phenotypes.

\section{Introduction}

Tubulins represent the major constituents of microtubules; they are dimeric proteins consisting of two closely a and $\beta$ related subunits encoded by tubulin genes (i.e., TUBA1A, TUBB2B, TUBB3, TUBB4A, TUBB2A, TUBB, TUB8A) [1]. Mutations in the $\mathrm{\alpha}$ - and $\beta$ - tubulin genes, related to the functional area of the protein involved, lead to a complex and wide spectrum of cerebral malformations defined "Tubulinopathies" [2-4]. Beta-III tubulin (TUBB3, MIM 602661) is the most dynamic $\beta$-tubulin isoform expressed in neurons, and is highly expressed in the central nervous system [5]. Mutations altering TUBB3, which is expressed in post-mitotic neurons but not glia, segregate into two distinct phenotypic groups: congenital fibrosis of the extraocular muscles (CFEOM), a congenital disorder in which maldevelopment of cranial nerve axons leads to ptosis (drooping eye lids) and restricted eye movements [6-8], and a spectrum of cortical dysplasias collectively termed malformations of cortical development (MCD), such as neuronal migration defects, complex cortical dysgenesis and gyral simplification, cerebellar vermis dysplasia, thinning or agenesis of corpus callosum, and oculomotor and olfactory nerve hypoplasia [9]. However, the relationship between TUBB3 and epileptic seizures had not been thoroughly investigated. Here, we reported a patient who presented with epilepsy and global developmental delay, and genetic analysis showed a novel de novo TUBB3 variant.

\section{Patients And Methods}

\subsection{Ethics Statement}

This study was approved by the Ethical Committee of Affiliated Hospital of Qingdao University. The boy's parents had given written informed consent to publish these cases details.

\subsection{Methods}

Biochemical studies, blood and urinary metabolic screenings, video electroencephalography (EEG) and magnetic resonance imaging (MRI) were performed. Video EEG monitoring was performed using a Nihon Kohden digital video-EEG-1100K instrument for about 4 hours, covering both awake and sleep states. The psychomotor development was assessed according to clinical judgment. Genetic analysis was performed by whole exome sequencing. The pathogenicity of the identified missense substitution was predicted based on the lack of such mutations in the control samples and on the conservation of substituted nucleotides and amino acids. We also predicted the functional alteration of the novel missense mutations using polymorphism phenotyping-2 (PolyPhen-2, http://genetics.bwh.harvard.edu/pph2/) and MutationTaster (http://www.muta-tiontaster.org/).

\section{Results}

\subsection{Case report}

Our patient is a 21-month-old boy, the first child (the third gestation) of nonconsanguineous healthy parents with unremarkable family history. Abortion was performed on the 50th day of first gestation due to absence of fetal heart rate. The second gestation aborted at $18^{+6}$ weeks due to cervical insufficiency. Pregnancy and perinatal of this child were uneventful and birth at term with a spontaneous vaginal delivery. Birth weight was $4.3 \mathrm{~kg}$. Developmental milestones were delayed. Crawl was achieved at 11 months, independent standing at 16 months, and unsupported walking with wadding gait at 19 months. Currently, the 21-month-old boy can walk independently with wadding gait for about 3 meters and can speak only several reduplicated words such as "baba, mama". The auxological parameters were within normal range with a weight of $12.5 \mathrm{~kg}$ (50th-75th centile), a height of $86 \mathrm{~cm}(50 \mathrm{th}-75 \mathrm{th}$ centile) and OFC of $46 \mathrm{~cm}$ (5th-10th centile). Photophobia and elliptic pupil of eyes were found by the parents at her several months old without special diagnosis and treatment. He had three febrile seizures since the one year of age, with a decreasing fever peak (39.9, 38.5 and 37.8 respectively), and two seizures occurred during the third febrile episode. This time, the child was admitted to our hospital for an afebrile convulsion during awake state, which manifested as blink, eyes slowly turning horizontally, clenched fists, right upper limb straighten and lift, left upper limb on the side of the body, limbs stiff and shaking with loss of consciousness, lasting for about 10 minutes. The results of neurological examination were unremarkable. Blood examinations revealed normal blood cell 
count and C-reactive protein level, and normal levels of serum ammonia, glucose and sodium and calcium. The EEG revealed multifocal spike and waves and slow waves discharges, predominantly in bilateral anterior regions (Fig. 1). Brain MRI disclosed a significantly hypoplastic corpus callosum (Fig. 2).

Chromosome karyotype, plasma amino acid and organic acid analyses were normal.

\subsection{Genetic analysis}

Mutation analysis showed a novel de novo heterozygous variant of TUBB3 (NM_006086), c.763G > A (p.V255I) in exon 4 (Fig. 3). Based on the Human Gene Mutation Database (HGMD), the variant was not reported before. The missense variant c.763G > A in TUBB3 affect evolutionarily conserved residues. It predicted by PolyPhen-2 to be "probably damaging" on protein function with a probabilistic score of 0.986 , and predicted by MutationTaster to be "disease causing" with a probabilistic score of 0.999 .

\section{Discussion}

Tubulin proteins play a key role in several cellular processes crucial for a proper cortical development during neuronal proliferation, migration, differentiation, cortical laminar organization and axonal guidance of the radial glia (axon outgrowth and maintenance) $[4,10]$. TUBB3 expression is greatest during periods of axon guidance and maturation; levels decrease in the adult central nervous system (CNS) but remain high in the peripheral nervous system (PNS) [6, 11]. Heterozygous missense mutations in TUBB3 have been implicated in various neurological disorders encompassing either isolated CFEOM3 (MIM 600638) or complex cortical dysplasia with other brain malformations 1 (CDCBM1) (MIM 614039). CFEOM encompasses several different inherited strabismus syndromes characterized by congenital restrictive ophthalmoplegia affecting extraocular muscles innervated by the oculomotor and/or trochlear nerves. If all affected members of a family have classic CFEOM with bilateral involvement and inability to raise the eyes above midline, the phenotype is classified as CFEOM1 (MIM 135700). CFEOM2 (MIM 602078) shows autosomal recessive inheritance. CFEOM3 is characterized by autosomal dominant inheritance of a more variable phenotype than classic CFEOM1. Individuals with CFEOM3 may not have bilateral involvement, may be able to raise the eyes above midline, or may not have blepharoptosis $[12,13]$. CDCBM is a disorder of aberrant neuronal migration and disturbed axonal guidance. Affected individuals have mild to severe mental retardation, strabismus, axial hypotonia, and spasticity. Brain imaging shows variable MCD, including polymicrogyria, gyral disorganization, and fusion of the basal ganglia, as well as thin corpus callosum, hypoplastic brainstem, and dysplastic cerebellar vermis. Extraocular muscles are not involved [9].

Although the clinical phenotype related to $T U B B 3$ has been widely reported, the description of seizures in patients with $T U B B 3$ mutations is rare. It might because that TUBB3 was involved primarily in axon guidance mechanisms and scantly associated with MCDs and, consequently, with low levels of epileptogenicity $[6,10]$. After reviewing the literature published previously, we found only 6 cases had seizures during the courses (Table 1) [9, 14-17]. It seemed that both the phenotype CFEOM and CDCBM could present epileptic seizures. Poirier et al. [9] reported 2 cases carrying TUBB3 mutations had seizures, consisting of refractory and multifocal epilepsy in one case, and occasional prolonged febrile seizures in another patient. And Chew et al. [14] and Oegema et al.[15] reported one case with complex partial seizures, respectively. Costain et al. [16] reported one patient with generalized tonic-clonic seizures and tonic spasms. Ziats et al. [17] found a child with epilepsy carrying TUBB3 mutation from 523 patients by clinical exome sequencing. All the 6 patients had intellectual disability and/or motor delay, as well as corpus callosum abnormalities. Ophthalmological symptoms (3/4 cases) and MCD in cranial MRI ( $3 / 4$ cases) were also observed. Similarly, our patient here had febrile seizures before and focal seizure this time, which was diagnosed as epilepsy in combination with an abnormal EEG. He had global developmental delay and the MRI showed hypoplastic corpus callosum. Recently, Xu et al. [18] reported that TUBB3 expression was increased in patients with temporal lobe epilepsy and experimental models of epileptic seizures, which supported that TUBB3 played an important role in regulating epileptic seizures via GABA-A receptor-mediated synaptic transmission and probably explained the rare epileptic cases described TUBB3 mutated patients. 
Table 1

Summary of four patients with seizures who carried TUBB3 mutation.

\begin{tabular}{|c|c|c|c|c|c|c|c|c|c|}
\hline Patient & Sex/age & $\begin{array}{l}\text { TUBB3 } \\
\text { mutation }\end{array}$ & $\begin{array}{l}\text { Age of } \\
\text { seizure }\end{array}$ & $\begin{array}{l}\text { Seizure } \\
\text { type }\end{array}$ & EEG & $\begin{array}{l}\text { Intellectual } \\
\text { disability/ motor } \\
\text { delay }\end{array}$ & $\begin{array}{l}\text { Corpus } \\
\text { callosum } \\
\text { abnormalities }\end{array}$ & Ophthalmological & Other M \\
\hline $\begin{array}{l}\text { Poirier } \\
\text { et al., } \\
2010^{[9]}\end{array}$ & $F / 1 y$ & $\begin{array}{l}\text { c. } 533 \mathrm{C}> \\
\mathrm{T}, \\
\text { p.T178M }\end{array}$ & neonatal & $\begin{array}{l}\text { Multifocal } \\
\text { epilepsy }\end{array}$ & N.a. & $\begin{array}{l}\text { Not } \\
\text { determined/severe }\end{array}$ & $\begin{array}{l}\text { Complete } \\
\text { agenesis }\end{array}$ & $\begin{array}{l}\text { Multidirectional } \\
\text { nystagmus/intermittent } \\
\text { strabismus }\end{array}$ & $\begin{array}{l}\text { Global } \subseteq \\
\text { disorgal }\end{array}$ \\
\hline $\begin{array}{l}\text { Poirier } \\
\text { et al., } \\
2010 \text { [9] }\end{array}$ & M/10y & $\begin{array}{l}\text { c. } 613 \mathrm{G}> \\
\text { A, }_{1} \\
\text { p.E205K }\end{array}$ & N.a. & $\begin{array}{l}\text { Prolonged } \\
\text { Febrile } \\
\text { seizures }\end{array}$ & N.a. & $\begin{array}{l}\text { Severe/Axial } \\
\text { hypotonia }\end{array}$ & Thin & Normal & polymic \\
\hline $\begin{array}{l}\text { Chew et } \\
\text { al., } \\
2013 \\
{[14]}\end{array}$ & $M / 9 y$ & $\begin{array}{l}\text { c. } 1228 \mathrm{G} \\
>\mathrm{A} \\
\text { E410K }\end{array}$ & $3 y$ & $\begin{array}{l}\text { Complex } \\
\text { partial } \\
\text { seizures }\end{array}$ & $\begin{array}{l}\text { Left } \\
\text { centrotemporal } \\
\text { and right } \\
\text { frontal sleep- } \\
\text { activated } \\
\text { spikes. }\end{array}$ & Yes/n.a. & yes & $\begin{array}{l}\text { Ptosis, exotropia, } \\
\text { restricted eye } \\
\text { movements }\end{array}$ & N.a. \\
\hline $\begin{array}{l}\text { Oegema } \\
\text { et al., } \\
2015 \\
{[15]}\end{array}$ & M/6y5m & $\begin{array}{l}\text { c. } 1070 \mathrm{C} \\
> \\
\text { T,P357L }\end{array}$ & N.a. & $\begin{array}{l}\text { Partial } \\
\text { complex } \\
\text { seizures }\end{array}$ & N.a. & $\begin{array}{l}\text { low end of } \\
\text { normal/severe }\end{array}$ & $\begin{array}{l}\text { Mildly } \\
\text { shortened }\end{array}$ & $\begin{array}{l}\text { Oculomotor apraxia, } \\
\text { strabismus }\end{array}$ & $\begin{array}{l}\text { Diffuse } \\
\text { irregulaı } \\
\text { gyration } \\
\text { sulcatio } \\
\text { multiple } \\
\text { shallow }\end{array}$ \\
\hline $\begin{array}{l}\text { Costain } \\
\text { et al., } \\
2019 \\
{[16]}\end{array}$ & $F / 14 y$ & $\begin{array}{l}\text { c. } 1172 \mathrm{G} \\
\text { > T, } \\
\text { R391L }\end{array}$ & N.a. & $\begin{array}{l}\text { generalized } \\
\text { tonic- } \\
\text { clonic } \\
\text { seizures, } \\
\text { tonic } \\
\text { spasms }\end{array}$ & $\begin{array}{l}\text { spike and } \\
\text { waves }\end{array}$ & Yes/Yes & Thin & N.a. & $\begin{array}{l}\text { Caudotr } \\
\text { cysts }\end{array}$ \\
\hline $\begin{array}{l}\text { Ziats et } \\
\text { al., } \\
2019 \\
{[17]}\end{array}$ & $\mathrm{M} / 5 \mathrm{y} 2 \mathrm{~m}$ & $\begin{array}{l}\text { c. } 1172 \mathrm{G} \\
\text { > T, } \\
\text { R391L }\end{array}$ & N.a. & N.a. & N.a. & Yes/Yes & agenesis & $\begin{array}{l}\text { visual cortical } \\
\text { impairment }\end{array}$ & N.a. \\
\hline $\begin{array}{l}\text { Our } \\
\text { patient }\end{array}$ & $\mathrm{M} / 1 \mathrm{y} 9 \mathrm{~m}$ & $\begin{array}{l}\text { c. } 763 G> \\
\text { A, V255I }\end{array}$ & $1 y 9 m$ & $\begin{array}{l}\text { Partial } \\
\text { seizures }\end{array}$ & $\begin{array}{l}\text { multifocal } \\
\text { spike and } \\
\text { waves and } \\
\text { slow waves }\end{array}$ & Yes/Yes & hypoplastic & $\begin{array}{l}\text { Photophobia and } \\
\text { elliptic pupil of eyes }\end{array}$ & No \\
\hline
\end{tabular}

F: female; M: male; N.a.: not available; y: years; m: months.

Of noting, our patient here had photophobia and elliptic pupil, but lacking of additional ophthalmological impairment indicated that ocular motility disorder, CFEOM3. Although intermittent or permanent nonparalytic strabismus had been reported previously [9], this was the first report of elliptic pupil in patients with TUBB3 mutations. We speculated that it might be due to fine oculomotor nerve defects resulting in damage to the intraocular muscle, considering that $T U B B 3$ mutations could affect extraocular muscles innervated by the oculomotor and/or trochlear nerves. However, there is no doubt that the exact mechanism needs further research.

It has been suggested that TUBB3 mutations reported to cause CFEOM or CDCBM. The former are not associated with cortical malformations, and the latter are not associated to CFEOM or other forms of ophthalmoplegia, suggesting that each set of mutations alters the microtubule functions in a specific fashion $[9,15,19]$. The genotype/phenotype correlations were assumed not only by the primary sequence of the protein, but also by the tertiary sequence and the three-dimensional arrangement of the protein [9]. In disagreement with this clinical stratification, our patient with a novel c.763G > A (p.V255I) of TUBB3 manifested as epilepsy with global neurodevelopmental delay, a mild ocular phenotype and hypoplastic corpus callosum, with no evidence of MCD and extraocular muscles involvement, which seemed to meet the diagnostic criteria of neither CFEOM nor CDCBM. Besides, two TUBB3 mutations (G71R and G98S) had been found in four patients with CFEOM, intellectual disability, and MCD [20]. Thus, tubulinopathies caused by TUBB3 might associate with a more wide range of clinical phenotypes such as intraocular muscle involvement, or merge the two distinct phenotypes (CFEOM and CDCBM) in the same patient, suggesting a common microtubule dysfunction shared by both phenotypes [20].

Consequently, our findings expanded the spectrum of TUBB3 phenotypes to global developmental delay, epilepsy, photophobia and elliptic pupil, and hypoplastic corpus callosum, without extraocular muscles involvement and MCD, which might be a less severe phenotype of TUBB3 mutations. It indicated that the phenotypic range of TUBB3 mutations might be more continuous than discrete, with a severity ranging from mild to severe. However, it was worth mentioning that the possibility of some clinical manifestations had not presented completely could not be excluded, considering the patient here was only 21 months old at the last follow-up. Further studies are needed to elucidate the complete spectrum of TUBB3-related phenotypes.

\section{Declarations}

\section{Ethics approval and consent to participate:}

The study was approved by the Ethical Committee of Affiliated Hospital of Qingdao University. Written informed consent was obtained from the parents/guardians of the patient for publication of this case report and any accompanying images. A copy of the written consent is available for review by the 
Editor of this journal.

\section{Consent for publication}

We obtained the written consent for publication from the guardian of the patients.

\section{Availability of data and materials}

The datasets generated and analyzed during the current study are all shown in the manuscript.

\section{Competing interests}

The authors declare no conflict of interest.

\section{Funding}

This work was supported by the Taishan Scholars Program of Shandong Province (NO.tsqn201909191), and Youth Fund of the Affiliated Hospital of Qingdao University (NO.QDFYQN2020014).

\section{Authors' contributions}

Conception and design of the study: JX, ZS, YZ; Acquisition and analysis of data: SM, ZY, CY, FL, KL; Drafting a significant portion of the manuscript or figures: JX. All authors have read and approved the manuscript.

\section{Acknowledgements}

We thank the patient and his families for participating

\section{References}

[1] Wu Q, Liu J, Fang A, Li R, Bai Y, Kriegstein AR, Wang X. The dynamics of neuronal migration. Adv Exp Med Biol. 2014; 800: 25-36. doi: 10.1007/978-94-0077687-6_2.

[2] Mutch CA, Poduri A, Sahin M, Barry B, Walsh CA, Barkovich AJ. Disorders of Microtubule Function in Neurons: Imaging Correlates. AJNR Am J Neuroradiol. 2016; 37(3): 528-35. doi: 10.3174/ajnr.A4552.

[3] Tischfield MA, Engle EC. Distinct alpha- and beta-tubulin isotypes are required for the positioning, differentiation and survival of neurons: new support for the 'multi-tubulin' hypothesis. Biosci Rep. 2010; 30(5): 319-330. doi: 10.1042/BSR20100025.

[4] Romaniello R, Zucca C, Arrigoni F, Bonanni P, Panzeri E, Bassi MT, Borgatti R. Epilepsy in Tubulinopathy: Personal Series and Literature Review. Cells. 2019; 8(7): 669. doi: 10.3390/cells8070669.

[5] Panda D, Miller HP, Banerjee A, Ludueña RF, Wilson L. Microtubule dynamics in vitro are regulated by the tubulin isotype composition. Proc Natl Acad Sci U S A. 1994; 91(24): 11358-11362. doi: 10.1073/pnas.91.24.11358.

[6] Tischfield MA, Baris HN, Wu C, Rudolph G, Van Maldergem L, He W, et al. Human TUBB3 mutations perturb microtubule dynamics, kinesin interactions, and axon guidance. Cell. 2010; 140(1): 74-87. doi: 10.1016/j.cell.2009.12.011.

[7] Demer JL, Clark RA, Tischfield MA, Engle EC. Evidence of an asymmetrical endophenotype in congenital fibrosis of extraocular muscles type 3 resulting from TUBB3 mutations. Invest Ophthalmol Vis Sci. 2010; 51(9): 4600-4611. doi: 10.1167/iovs.10-5438.

[8] Dentici ML, Maglione V, Agolini E, Catena G, Capolino R, Lanari V, et al. TUBB3 E410K syndrome: Case report and review of the clinical spectrum of TUBB3 mutations. Am J Med Genet A. 2020; 182(8): 1977-1984. doi: 10.1002/ajmg.a.61719.

[9] Poirier K, Saillour Y, Bahi-Buisson N, Jaglin XH, Fallet-Bianco C, Nabbout R, et al. Mutations in the neuronal ß-tubulin subunit TUBB3 result in malformation of cortical development and neuronal migration defects. Hum Mol Genet. 2010; 19(22): 4462-4473. doi: 10.1093/hmg/ddq377.

[10] Romaniello R, Arrigoni F, Bassi MT, Borgatti R. Mutations in a- and $\beta$-tubulin encoding genes: implications in brain malformations. Brain Dev. 2015; 37(3): 273-280. doi: 10.1016/j.braindev.2014.06.002.

[11] Jiang YQ, Oblinger MM. Differential regulation of beta III and other tubulin genes during peripheral and central neuron development. J Cell Sci. 1992; 103 ( Pt 3): 643-651.

[12] Yamada K, Chan WM, Andrews C, Bosley TM, Sener EC, Zwaan JT, et al. Identification of KIF21A mutations as a rare cause of congenital fibrosis of the extraocular muscles type 3 (CFEOM3). Invest Ophthalmol Vis Sci. 2004; 45(7): 2218-2223. doi: 10.1167/iovs.03-1413.

[13] Heidary G, Engle EC, Hunter DG. Congenital fibrosis of the extraocular muscles. Semin Ophthalmol. 2008; 23(1): 3-8. doi:10.1080/08820530701745181. 
[14] Chew S, Balasubramanian R, Chan WM, Kang PB, Andrews C, Webb BD, et al. A novel syndrome caused by the E410K amino acid substitution in the neuronal $\beta$-tubulin isotype 3. Brain. 2013;136(Pt 2): 522-535. doi: 10.1093/brain/aws345.

[15] Oegema R, Cushion TD, Phelps IG, Chung SK, Dempsey JC, Collins S, et al. Recognizable cerebellar dysplasia associated with mutations in multiple tubulin genes. Hum Mol Genet. 2015; 24(18): 5313-5325. doi: 10.1093/hmg/ddv250.

[16] Costain G, Cordeiro D, Matviychuk D, Mercimek-Andrews S. Clinical Application of Targeted Next-Generation Sequencing Panels and Whole Exome Sequencing in Childhood Epilepsy. Neuroscience. 2019; 418: 291-310. doi: 10.1016/j.neuroscience.2019.08.016.

[17] Ziats MN, Ahmad A, Bernat JA, Fisher R, Glassford M, Hannibal MC, et al. Genotype-phenotype analysis of 523 patients by genetics evaluation and clinical exome sequencing. Pediatr Res. 2020; 87(4): 735-739. doi: 10.1038/s41390-019-0611-5.

[18] Xu X, Shangguan Y, Lu S, Wang W, Du C, Xiao F, et al. Tubulin B-III modulates seizure activity in epilepsy. J Pathol. 2017; 242(3): 297-308. doi: 10.1002/path.4903.

[19] Bahi-Buisson N, Poirier K, Fourniol F, Saillour Y, Valence S, Lebrun N, et al. The wide spectrum of tubulinopathies: what are the key features for the diagnosis? Brain. 2014; 137(Pt 6): 1676-700. doi: 10.1093/brain/awu082.

[20] Whitman MC, Andrews C, Chan WM, Tischfield MA, Stasheff SF, Brancati F, et al. Two unique TUBB3 mutations cause both CFEOM3 and malformations of cortical development. Am J Med Genet A. 2016; 170A(2): 297-305. doi: 10.1002/ajmg.a.37362.

\section{Figures}

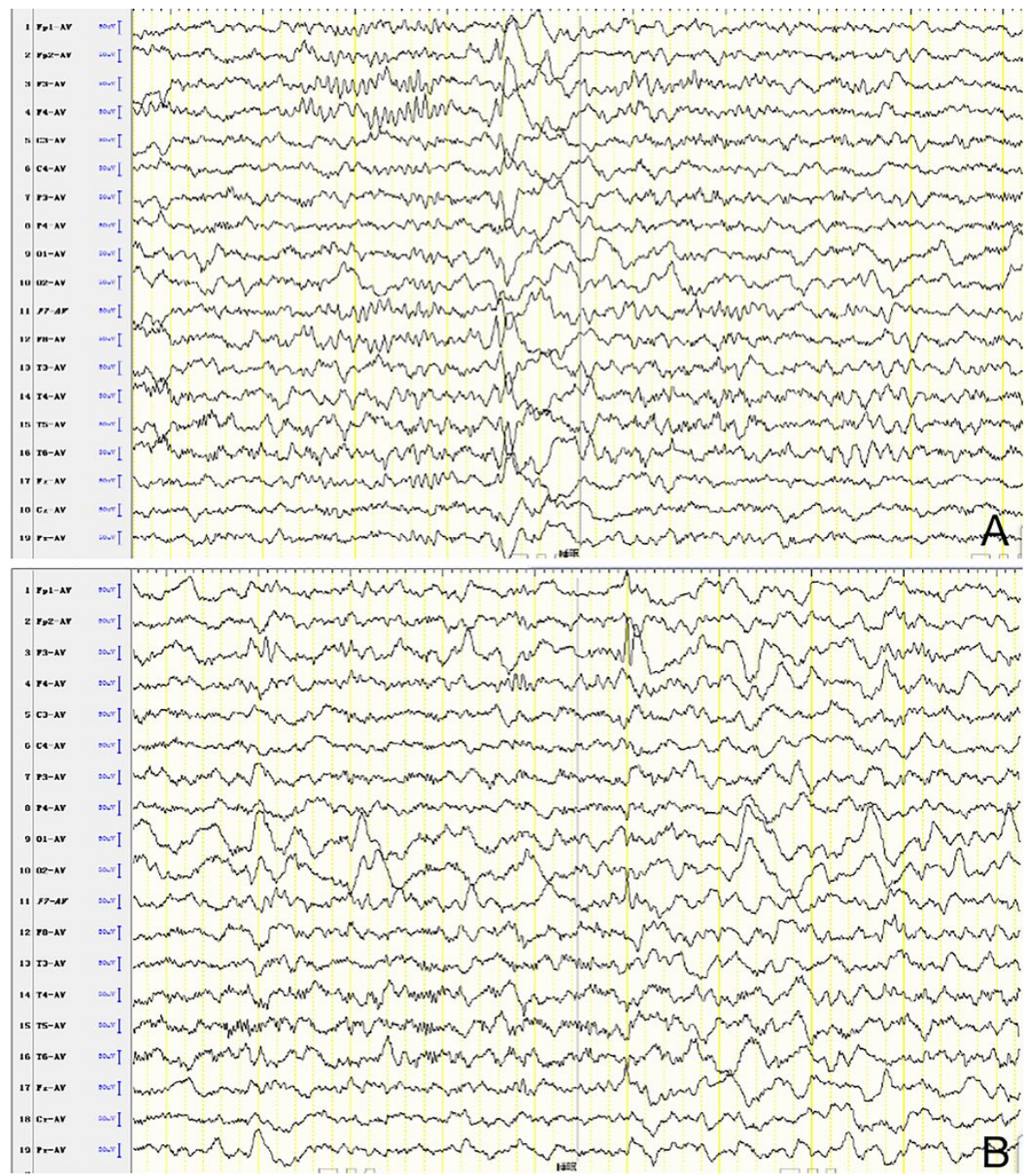

\section{Figure 1}

The EEG revealed multifocal spike and waves and slow waves discharges, predominantly in bilateral anterior regions. 


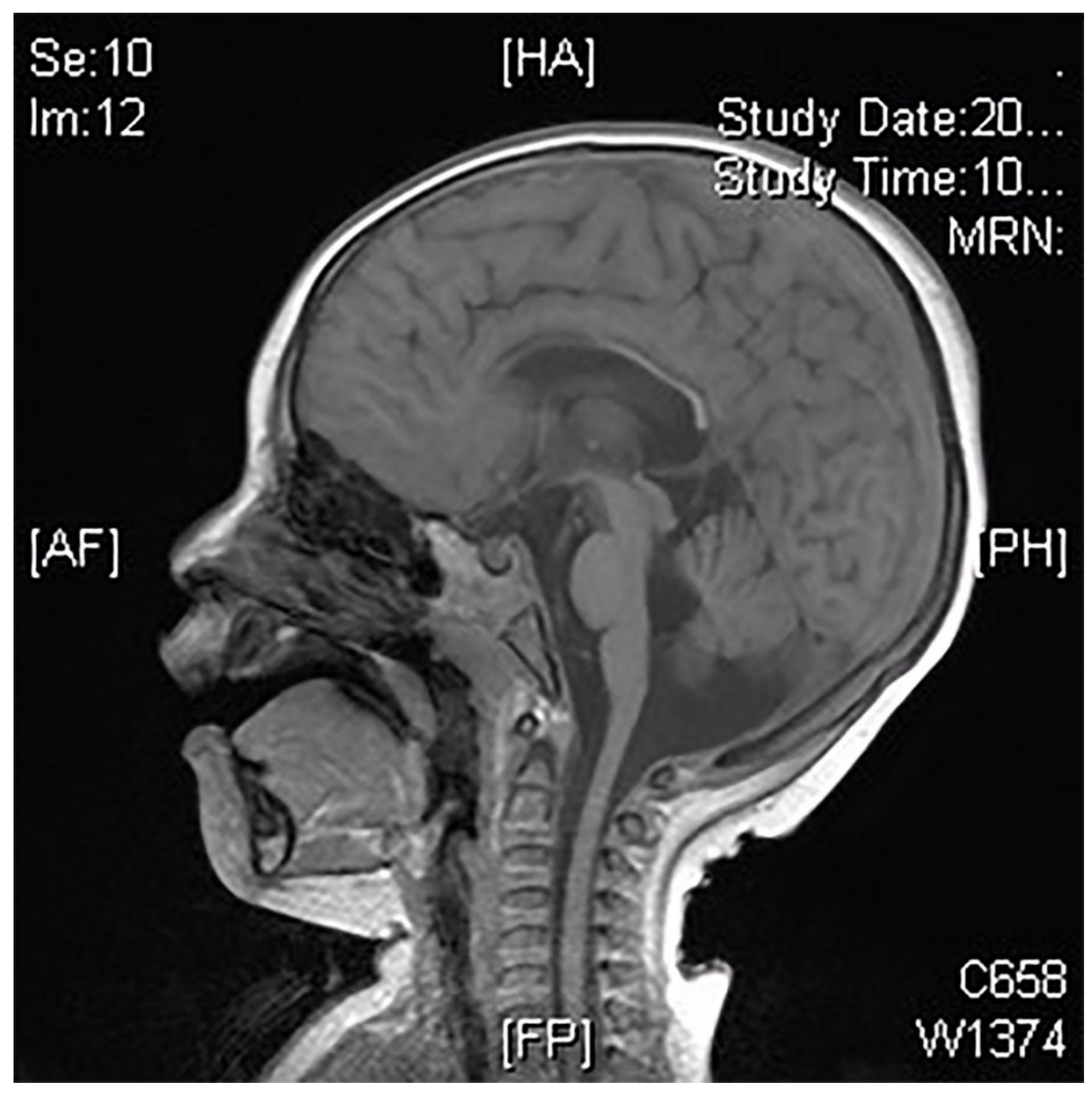

Figure 2

Brain MRI disclosed a significantly hypoplastic corpus callosum. 


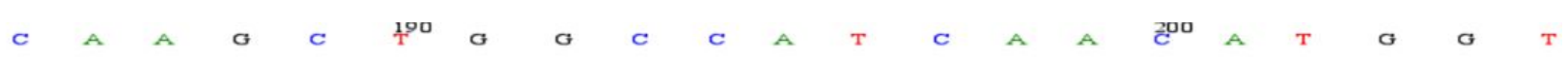

c.763G >A
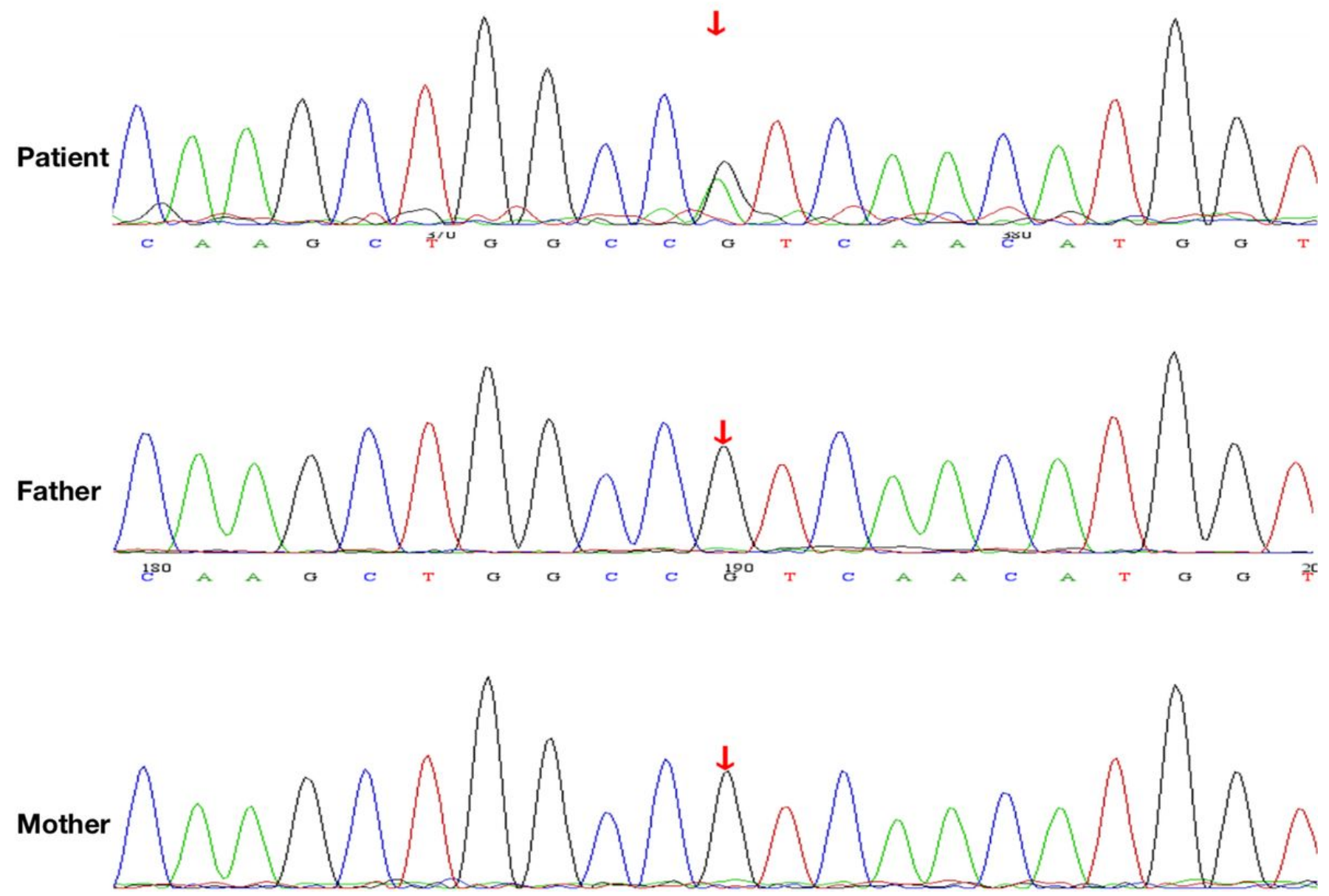

Figure 3

A de novo heterozygous variant of TUBB3 (NM_006086), c.763G>A (p.V255I) in our patient. 